\title{
Hereditary hyperbilirubinemia: An original study of four cases with review of literature.
}

\author{
Dr. Aarti B.Bhattacharya 1,Dr.Shamima 2,Dr.S K Gupta 3. \\ 1 Professor \&.2 Assist.Prof. Pathology Dept. Hind Institute Of Medical Sciences,Safedabad \\ Barabanki.(UP)INDIA \\ 3.Associate Prof. Dept.of Skin \&VD. Hind Institute Of Medical Sciences,Safedabad Barabanki.(UP)INDIA
}

\begin{abstract}
Crigler Najjar Syndrome (CNS) a congenital non hemolytic hyperbilirubinemia is very rare with an incidence of around 1 in 1,000,000 births associated with a complete hepatic deficit of bilirubin glucoronosyltransferase activity. Herein we present a study of four cases: three siblings from the same family and one independent case. All the three siblings of the same family had history of persistent neonatal unconjugated hyperbilirubinemia, out of which the eldest female sibling died of seizures with severe hyperbilirubinemia giving a high suspiscion of kernicterus. Second eldest and the youngest son had congenital unconjugated hyperbilirubinemia. The third born male child was normal. The independent case had history of persistent mild hyperbilirubinemia since twelve years of age.
\end{abstract}

Key words: Unconjugated hyperbilirubinemia, Uridine diphosphate glucoronosyltransferase deficiency, severe jaundice, phototherapy, phenobarbitol, liver transplantation.

\section{Introduction:}

Crigler Najjar Syndrome is a disorder characterized by familial chronic nonhemolytic unconjugated hyperbilirubinemia caused by genetic lesion. It has two types: Type I CNS and Type II CNS. Type I has recessive transmission [2] while type II has both dominant and recessive traits [1]. Clinically negligible Gilbert's syndrome is the other familial hyperbilirubinemia disorder with an incidence of 3 to $10 \%$ [3].

\section{Material and methods:}

The present original study of four cases was conducted at the department of Pathology, Hind Institute of Medical Sciences, Safedabad, Barabanki (UP), India. Patient's baseline pathological tests were performed along with hemolytic profile, liver function test, liver biopsy and cytogenetic studies with detailed family history including birth history and milestones.

\section{Results and Discussion:}

Only a few hundred cases of Crigler-Najjar Syndrome have been described in the literature so far. The affected neonate shows early intense jaundice due to unconjugated bilirubin. Physical examination does not reveal any defect. $[1,2]$

In our study parents of first three cases gave history of consanguineous marriage. The eldest female sibling had severe icterus and jaundice soon after birth (CASE 1). There was no history of preterm delivery or septicemia. The neonate deteriorated and succumbed to seizures on the sixth day post partum.No investigations could be carried out in this case. The other two siblings (second and fourth born males - CASES $2 \& 3$ ) developed icterus in infancy. Icterus and jaundice increased under conditions of stress and the physical growth of two was affected. The third born male child was normal. According to our studies the three siblings are seen to have recessive transmission from parents. All the investigations done in these two cases turned out to be within normal limits except for bilirubin levels. The fourth case of the study finally diagnosed as Gilbert's Syndrome, presented with history of icterus since the age of twelve years with complaint of generalized weakness. The investigation reports are tabulated in Table 1.

Table 1: Investigations Of The Three Live Cases.

\begin{tabular}{|l|l|l|l|}
\hline INVESTIGATIONS & CASE 2 & CASE 3 & CASE 4 \\
\hline HB & $13.3 \mathrm{gm} \%$ & $13.6 \mathrm{gm} \%$ & $11.4 \mathrm{gm} \%$ \\
\hline RBC & $4.4 \mathrm{millions} / \mathrm{cumm}$ & $4.8 \mathrm{millions} / \mathrm{cumm}$ & $4.0 \mathrm{millions} / \mathrm{cumm}$ \\
\hline Reticulocyte count & $0.8 \%$ & $0.6 \%$ & $2.0 \%$ \\
\hline $\mathrm{MCV}$ & $80.0 \mathrm{fl} / \mathrm{cumm}$ & $82.0 \mathrm{fl} / \mathrm{cumm}$ & $63.3 \mathrm{fl} / \mathrm{cumm}$ \\
\hline $\mathrm{MCH}$ & $27.5 \mathrm{gm} / \mathrm{dl}$ & $28.0 \mathrm{gm} / \mathrm{dl}$ & $19.5 \mathrm{gm} / \mathrm{dl}$ \\
\hline $\mathrm{MCHC}$ & $33.0 \%$ & $33.4 \%$ & $31.0 \%$ \\
\hline ESR & $7 \mathrm{~mm}$ at $1 \mathrm{hr}$ & $8 \mathrm{~mm}$ at $1 \mathrm{hr}$ & $11 \mathrm{~mm} \mathrm{at} 1 \mathrm{hr}$ \\
\hline TLC & 7000 cells/cumm & $6,500 \mathrm{cells} / \mathrm{cumm}$ & $6,700 \mathrm{cell} / \mathrm{cumm}$ \\
\hline
\end{tabular}


Hereditary hyperbilirubinemia: An original study of four cases with review of literature.

\begin{tabular}{|c|c|c|c|}
\hline PLATELET & 2.0 lakhs/cumm & 2.3 lakhs/cumm & 1.8 lakhs/cumm \\
\hline COOMB'S TEST & NEGATIVE & NEGATIVE & NEGATIVE \\
\hline G6PD TEST & NEGATIVE & NEGATIVE & NEGATIVE \\
\hline TOTAL BILIRUBIN & $12 \mathrm{mg} / \mathrm{dl}$ & $6.7 \mathrm{mg} / \mathrm{dl}$ & $2.6 \mathrm{mg} / \mathrm{dl}$ \\
\hline INDIRECT BILIRUBIN & $11.38 \mathrm{mg} / \mathrm{dl}$ & $6.20 \mathrm{mg} / \mathrm{dl}$ & $2.1 \mathrm{mg} / \mathrm{dl}$ \\
\hline ALP & $296.8 \mathrm{meq} / 1$ & $320 \mathrm{meq} / 1$ & $135 \mathrm{meq} / 1$ \\
\hline ALBUMIN & $3.8 \mathrm{gm} / \mathrm{dl}$ & $4.0 \mathrm{gm} / \mathrm{dl}$ & $3.0 \mathrm{gm} / \mathrm{dl}$ \\
\hline ALT & $43 \mathrm{meq} / 1$ & $42 \mathrm{meq} / \mathrm{l}$ & $20.9 \mathrm{meq} / 1$ \\
\hline AST & $40 \mathrm{meq} / \mathrm{l}$ & $40 \mathrm{meq} / \mathrm{l}$ & $30.4 \mathrm{meq} / 1$ \\
\hline $\mathrm{LDH}$ & $112 \mathrm{u} / \mathrm{l}$ & $115 \mathrm{u} / 1$ & $120 \mathrm{u} / \mathrm{l}$ \\
\hline PT & $14.0 \mathrm{sec}$ & $13.0 \mathrm{sec}$ & $13.0 \mathrm{sec}$ \\
\hline AMYLASE & $30 \mathrm{u} / 1$ & $34 \mathrm{u} / 1$ & $42 \mathrm{u} / 1$ \\
\hline $\mathrm{TSH}$ & $1.56 \mathrm{mU} / \mathrm{L}$ & $2.0 \mathrm{mU} / \mathrm{L}$ & $3.4 \mathrm{mU} / \mathrm{L}$ \\
\hline Anti Thyroglobulin $\mathrm{Ab}$ & NEGATIVE & NEGATIVE & NEGATIVE \\
\hline Anti Microsomal AB & NEGATIVE & NEGATIVE & NEGATIVE \\
\hline $\mathrm{HBsAg}$ & NEGATIVE & NEGATIVE & NEGATIVE \\
\hline Anti HCV & NEGATIVE & NEGATIVE & NEGATIVE \\
\hline BILE PIGMENTS (URINE) & Absent & Absent & Absent \\
\hline
\end{tabular}

Peripheral blood smears(cases 1 and 2-NAD, case 3-Microcytic Hypochromic Anemia), Hbelectrophoresis, abdominal ultrasonography and upper GIT endoscopy did not reveal any abnormality. Liver biopsy of all the live cases revealed nonspecific histological findings. In all the three live cases bile obtained from duodenal aspiration contained conjugated bilirubin.

It is known that uridine diphosphate glucoronosyltranferase (UGT) conjugates bilirubin with glucoronic acid in the endoplasmic reticulum of hepatocytes to convert it into water soluble conjugated bilirubin that is excreted in bile. In CNS I the hepatic UGT activity is completely absent. In CNS II less than 10\% hepatic UGT activity is retained. Thus CNS I patients suffer from a very severe hyperbilirubinemia that often is fatal in the first few months to two years of life. The type I CNS patients require liver transplant for survival however in CNS II residual hepatic UGT activity can be enhanced by Phenobarbital therapy. CNS II patients are at risk of encephalopathy whenever they are administered anesthetics or certain hepatotoxic drugs or in the presence of septicemia. In CNS II majority of the patients survive unto adulthood without complications (3).

The hepatic UGT activity was not performed in our cases. In all the live three cases $\left(2^{\text {nd }}\right.$, $3^{\text {rd }}$ and $4^{\text {th }}$ case) Phenobarbital challenge test was done which showed reduced bilirubin levels as shown in Table 2.

Table 2: Phenobarbital Challenge Test Results In The Three Live Cases.

\begin{tabular}{|l|l|l|l|l|l|c|}
\hline INVESTIGATION & CASE 2 ( CNS II) & CASE 3 ( CNS II) & CASE 4 (GS) \\
\hline & BEFORE PB & AFTER PB & BEFOREPB & AFTER PB & BEFORE PB & AFTER PB \\
\hline $\begin{array}{l}\text { TOTAL } \\
\text { BILIRUBIN }\end{array}$ & 12.0 & 4.50 & 6.70 & 2.45 & 2.8 & 1.0 \\
\hline $\begin{array}{l}\text { INDIRECT } \\
\text { BILIRUBIN }\end{array}$ & 11.38 & 3.85 & 6.20 & 1.90 & 2.0 & 0.9 \\
\hline
\end{tabular}

Crigler Najjar syndrome compirises two types: Type I CNS and Type II CNS. Type I CNS patients are unaffected by phenobarbitol induction therapy whereas three weeks of phenobarbitol induction therapy can lower bilirubinemia by 60 to $70 \%$ in CNS Type II. Treatment of Type II CNS consists of daily phenobarbitol while that of type I requires phototherapy at hospital in early neonatal period then at home for 10 to 12 hours per day. The only effective treatment for type I is liver transplantation .(7,8). Children with type I CNS have a permanent risk of neurological complication kernicterus. Children with type II disease also has this risk but to a lesser extent. Type I CNS occurs with autosomal recessive inheritance. Type II may occur as recessive or dominant trait. Neonates with CNS I have deep icterus and jaundice at or soon after birth that persist and if not treated, it is fatal from first few months to two years of life. In CNS II jaundice may not manifest until later in infancy or child hood. Phenobarbitol challenge test differentiates between these two types. (11) Phenobarbitol (UGT inducer) reduces serum bilirubin in CNS II to $25 \%$ after the second half of first year of life. (12) Serum bilirubin concentration will decrease to normal levels in patients with Gilbert syndrome in contrast to that of CNS I I. Whereas no response to phenobarbitol is seen in CNS I. In normal subjects serum bilirubin levels ranges from 0.3 to $1.0 \mathrm{mg} / \mathrm{dl}$, in Gilbertsyndrome serum bilirubin rarely exceeds 3-4 mg/dl. In CNS II the bilirubin level ranges from 6 to $20 \mathrm{mg} / \mathrm{dl}$, and in CNS I it ranges from 15 to $50 \mathrm{mg} / \mathrm{dl}$. In our cases conclusively we had excluded all other causes of indirect 
hyperbilirubinemia and thus the diagnoses of CNS II in second and third case and Gilbert's Syndrome in the fourth case was established. We feel that the first case in our study had CNS I.

Bilirubin-UGT (1) ie UGT1A1 is the only isoform that significantly contributes to the conjugation of bilirubin. Lesions in the gene encoding bilirubin - UGT1A1 result in complete inactivation of the enzyme resulting in Crigler-Najjar Syndrome Type I(CNI). Where as partial inactivation of the enzyme causes Crigler-Najjar Syndrome TypeII (CNII).These two syndromes are rare autosomal reccessively inherited conditions. (1,2)Inactivation of enzyme leads to accumulation of unconjugated bilirubin in the serum Severe hyperbilirubinemia as seen in CNI causes bilirubin encephalopathy(Kernicterus). Kernicterus can be fatal in first few months of life or may leave behind permanent neurological sequelae.(1,2)In contrast to Crigler-Najjar syndrome,Gilbert Syndrome is a common inherited condition that is characterized by mild hyperbilirubinemia.(3) An insertional mutation of the TATAA element upstream to UGT1A1 results in a reduced level of expression of the gene.Several structural mutations of UGT1A1 like G71R substitution have been reported to cause mild reduction of UGT activity toward bilirubin causing mild hyperbilirubinemia consistent with Gilbert syndrome (3).

It has been observed that when the normal allele of a heterozygote carrier for Crigler-Najjar type structural mutation contains a Gilbert type promoter, then intermediate levels of hyperbilirubinemia consistent with the diagnosis of CN-II may be observed.(3)

Genetic workup:

Case $2 \&$ case 3

Clinical diagnosis - Criggler Najjar syndrome Type II

Test performed- Complete sequencing of UGT1A1 gene

Result- Both patients are Homozygous for A[TA]7TAA variant in the UGT1A1 gene

Date - 10th Aug2013

Method

Genomic DNA was extracted from blood using commercial kits. PCR was performed for the promoter, 5' untranslated region, all exons (covering intron-exon boundaries) and 3' untranslated region of the UGT1A1 gene. The PCR was followed by purification using ExoSAP-IT and then Sanger sequencing using Big Dye Terminator sequencing chemistry. Bidirectional Sequencing was performed on automated capillary sequencer (ABI). The sequence chromatograms obtained were compared with wild type.

Results

The patients were found to be homozygous for A[TA]7TAA variant in the promoter of the UGT1A1 gene. No pathogenic variant was seen in the 5' untranslated region, all exons (covering intron-exon boundaries) and 3' untranslated region of the UGTIAI gene.

Interpretation

The persistent jaundice of the patient could be a manifestation of severe form of Gilbert syndrome, provided other known causes of persistent jaundice have been ruled out.

Case 4:

Name of patient- Satyendra Kumar 27 years/ male

Name of father - Ram Khilawan, 59 yrs

Name of mother - Geeta Devi , 52 yr

Name of brother - Jeetendra, 30 ys

Clinical diagnosis - Suspected Gilbert syndrome in Satyendra

Date of report - 18th June 2013

Method

Genomic DNA was extracted from peripheral blood using commercial extraction kit. The promoter region of UGT1A1 gene was amplified by PCR and sequenced using Sanger method on automated capillary sequencer. BLAST analysis was performed and the TA repeats were manually counted.

Results

Satyendra has the following alleles A(TA)7TAA/ A(TA)6TAA; his father has the following alleles A(TA)7TAA/A(TA)7TAA; mother has the following alleles - A(TA)7TAA/A(TA)6TAA and his brother has the following alleles - A(TA)7TAA/A(TA)7TAA.

Figure 1 showing - Satyendra has the following alleles - A(TA)7TAA/ A(TA)6TAA

Figure 2: showing Ram Khilawan(Father) has the following alleles- A(TA)7TAA/A(TA)7TAA

Figure 3: showing Geeta Devi (Mother) has the following alleles A(TA)7TAA/ A(TA)6TAA 
Figure 4: showing Jeetendra Kumar(Brother) showing the following alleles - A(TA)7TAA/A(TA)7TAA

\section{Interpretation}

Gilbert syndrome is associated with the polymorphism A(TA)7TAA/A(TA)7TAA in the promoter region of the UGT1A1 gene in most cases. However, in case, other causes of jaundice has been ruled out, the alleles A(TA)7TAA/A(TA)6TAA could also be implicated in Gilbert syndrome. Clinical correlation is suggested

Signed by

Dr Parag Tamhankar, DM, MD, DNB, DCH, FCPS

Scientist D

Genetic Research Center, NIRRH

Thus cases II and III revealed no pathogenic variant of UGT1A1 gene and so have been termed to have severe form of Gilbert's Syndrome. Clinically the above two cases resembled CNS II that we were tempted to repeat the genetic tests, but the boys' parents declined for the same.

Case IV was observed to have Gilbert's Syndrome.

\section{Treatment aspect:}

CNS I requires orthotopic liver transplantation(14) and until then phototherapy to combat the high levels of serum bilirubin $(7,8)$. Phototherapy is not possible life long because as age advances the skin becomes thick and light cannot pass effectively. Gene repair therapy is still in experimental stage.(13)

It is commonly thought that CNS II patients do not require treatment but these patients should take adequate precautions as for hepatotoxic drugs, anaesthetics and septicemia etc. Also some patients are aware of their jaundiced skin, in such cases low doses of phenobarbitol helps in inducing UGT1A1 and reducing indirect hyperbilirubinemia. $(7,8)$.

\section{Conclusion:}

It is very important to discover a new effective, long acting and safe drug that induces UGT1A1 in CNS II and Gilbert syndrome's patients. Patients should be well educated about their disease and counseled.

\section{References:}

[1]. Analysis of Bilirubin uridine $5-^{1}$ diphosphate(UDP) glucuronosyl transferase gene mutatins.[J Human gene1998]

[2]. Spectrum of UGT1A1 mutations in C N S patients.[Hum Mutat.2005]

[3]. Genetic polymorphism of bilirubin uridine diphospha te gluronosyl transferase.[J Gast roe nterology,Hepa tology 2004]

[4]. (Review)Genetic lesion of bilirubin uridine diphosphate glucuronosyl transferase.[Human Mutat.2000]

[5]. UDP-glucuronosyl transferases: gene structures of UGT1 and UGT2 families. Methods Enzymol.2005,400:1-22.OwensIS,Basu NK,BanerjeeR

[6]. Crigler-Najjar Syndrome typeII.Indian J Pedia.Nov 2004;71(11):1043[medline],Gupta R,Parashar Y

[7]. Orlistat treatment of unconjugated hyperbilirubinemia in Crigler-Najjar disease: a randomized controlled trial.Pediat.Res.Dec.2007;62(6):725-30[Medline]Hafkamp AM,Nelisse-Haak R,SinaasappelM,Oude ElferinkRP,Verkade HJ

[8]. Diagnosis and management of Crigler-Najjar Syndrome.

Eur.J Paediatr.Dec1999;158 Suppl2:S89-94[Medline]Jansen PL

[9]. Genetic diseases of bilirubin metabolism:the inherited unconjugated hyperbilirubinemia.J Hepatol.Sep1996;25(3):398-404[Medline]JansenPL

[10]. Crigler-Najjar Syndrome,1952-2000:learning from parents and patients about a very rare disease and using the internet to recruit patients for studies.Paediatrics.May2000;105(5):1152-3[Medline]Lucey JF,Suresh GK,Kappas

[11]. The hereditary hyperbilirubinaemias.Baillieres Clin Gastroenterol.J1998;12(2):35567.[Medline]NowickiMJ,Poley JR.

[12]. Crigler-Najjar Syndrome in the Netherlands:identification of four novel UGT1A1 alleles,genotypephenotype correlation, and functional analysis of 10 missense mutants.Hum Mutat.Jan 2010;31(1):52$9[$ Medline] SneitzN et al 
[13]. Towards liver directed gene therapy for Crigler-Najjar Syndrome.Curr Gene Ther.Apr.2009;9(2):7282[Medline] MirandaPS et al.

[14]. Liver cell transplantation for Crigler-Najjar typeI:update and perspectives.World J Gastroenterol.June14 2008;14(22):3464-70[Medline][Full Text] LysyPA,Najimi M,Stephenne X et al

[15]. Hematologically important mutations:bilirubin UDP-glucuronosyl transferase gene mutations in Gilbert and Crigler-Najjar Syndromes. Blood Cells Mol Dis.Jan-Feb2006;36(1)77-80[Medline]Costa E. 